\title{
O TERREIRO DE JONGO E A CIDADE: QUINTAL COMO RECRIAÇÃO ESPACIAL DE RESISTÊNCIA FAMILIAR NEGRA EM CAMPOS DOS GOYTACAZES-RJ
}

THE TERREIRO DE JONGO AND THE CITY:

THE BACKYARD AS SPATIAL RE-CREATION OF A BLACKFAMILY RESISTANCE IN CAMPOS DOS GOYTACAZES - RJ

\section{Tarianne da Silva Pinto Bertoza}

tari_bertoza@yahoo.com.br

Mestre em Políticas Sociais - UENF

ORCID: https://orcid.org/0000-0003-3355-4053

\section{Lilian Sagio Cezar}

lsagio@uenf.br

Professora do Programa de Pós-Graduação em Políticas Sociais - UENF

ORCID: https://orcid.org/0000-0001-8737-9946

\author{
Maria Clareth Gonçalves Reis \\ clareth@uenf.br \\ Professora do Programa de Pós-Graduação em Políticas Sociais - UENF \\ ORCID: https://orcid.org/0000-0001-5165-0239
}

\section{(C) $\odot \Theta(0)$}

Esta obra está licenciada sob uma licença Creative Commons Attribution-NonCommercial-ShareAlike 4.0 International License.

\section{RESUMO}

O presente artigo é resultado das reflexões do projeto de extensão do Núcleo de Estudos Afro-Brasileiros e Indígenas - NEABI/UENF, que teve como desdobramento a pesquisa de mestrado desenvolvida junto ao Programa de Pós-Graduação em Políticas Sociais da Universidade Estadual do Norte Fluminense Darcy Ribeiro - UENF. Esse artigo tem como objetivo descrever e analisar o jongo local enquanto expressão cultural e, concomitantemente, patrimônio cultural de natureza imaterial do Brasil, a partir da trajetória de vida e memórias de Geneci Maria da Penha, conhecida como mestra jongueira Noinha, de Campos dos Goytacazes, interior do estado do Rio de Janeiro. Partimos da trajetória de vida da mestra jongueira, considerando as relações traçadas por ela no seu terreiro de jongo para discutir questões relacionadas à religiosidade, ao preconceito racial sofrido, bem como algumas das táticas de resistência vivenciadas e desenvolvidas pela mestra frente às contingências cotidianas.

Palavras-chave: jongo; tradição familiar; religiosidade. 


\section{ABSTRACT}

This article is the result of the reflections of the extension project of the Center for Afro-Brazilian and Indigenous Studies - NEABI / UENF from which the master's research developed with the Post-Graduate Program in Social Policies of the State University of the North Fluminense Darcy Ribeiro - UENF resulted. The aim is to describe and analyze the local jongo as a cultural expression and, at the same time, intangible cultural heritage of Brazil, based on the life trajectory and memories of Geneci Maria da Penha, known as master jongueira Noinha, from Campos dos Goytacazes, in the inaland region of the state of Rio de Janeiro. We have started from her life trajectory, considering the relationships she established in her terreiro de jongo to discuss issues related to religiosity, the racial prejudice suffered, as well as some of the resistance tactics experienced by the master in face of everyday contingencies.

Keywords: jongo; family tradition; religiosity.

\section{INTRODUÇÃO}

O percurso desta pesquisa foi resultado de um constante tatear, de aproximações sucessivas que nos direcionaram sempre a novos caminhos. No início, imaginávamos estar realizando um trabalho especificamente sobre o jongo, porém, esse tatear foi sendo, cada vez mais, acrescido de outras reflexões. De fato, tudo começou com o jongo, mas é impossível falar dele sem falar de quem o vivencia e o mantém. Nascida em 10 de agosto de 1944, Geneci Maria da Penha, mais conhecida como Noinha, é herdeira e mantenedora de saberes e fazeres do jongo, tanto pela parte da família materna quanto da família paterna, tendo seguido matriz matrilinear e assumido a responsabilidade de manutenção e prática dessa herança a partir do falecimento de sua mãe, Maria Antônia Balbino da Penha.

O jongo de Noinha é reconhecido como Patrimônio Cultural do $\mathrm{Mu}-$ nicípio de Campos dos Goytacazes-RJ. Essa cidade, localizada ao norte do estado do Rio de Janeiro, às margens do caudaloso rio Paraíba do Sul, tem como marca as violências do passado colonial, sustentado econômica e socialmente pela escravidão de pessoas negras que trabalharam nas lavouras e engenhos de açúcar ali construídos. Segundo Lima (1981), para a região foram trazidos grande contingente de negros, que chegaram a constituir 54,38\% de sua população em 1816 (LIMA, 1981, p. 87).

Segundo o Dossiê Jongo no Sudeste (2007), o jongo constitui:

Uma forma de expressão que integra percussão de tambores, dança coletiva e elementos mágico-poéticos. Tem suas raízes nos saberes, ritos e crenças dos povos africanos, sobretudo os de língua banto. É cantado e tocado de diversas formas, dependendo da comunidade que o pratica. Consolidou-se entre os escravos que trabalhavam nas lavouras de café 
e cana-de-açúcar localizadas no Sudeste brasileiro, principalmente no vale do Rio Paraíba do Sul. É um elemento de identidade e resistência cultural para várias comunidades e também espaço de manutenção, circulação e renovação do seu universo simbólico (IPHAN, 2007, p. 11).

Tanto a palavra cantada como a tradição oral são fundamentais para o jongo. Praticado como diversão, mas também comportando aspectos religiosos, "o termo jongo refere-se não apenas à dança, mas também às cantigas que a acompanham" (PACHECO, 2007, p. 25), conhecidas como pontos. Os pontos de jongo possuem uma linguagem cifrada, compreensível para os participantes, porém, ininteligível para os de fora, daí seu caráter enigmático. A disposição dos participantes em roda, os tambores, os pontos, as narrativas sobre os efeitos dos pontos, a reverência aos ancestrais, são elementos que comunicam, por meio da palavra cantada, embalada pelo ritmo do tambor e dos movimentos.

Os pontos de jongo foram cuidadosamente estudados por Ribeiro (1984), que ressaltou o mistério carregado nos versos. De acordo com a autora, os pontos podem ter a seguinte classificação:

ponto de louvação - no início, para louvação; ponto de saudação - para saudar ou "saravá" alguém; ponto de visaria ou bizarria - para alegrar a dança; ponto de despedida - para o final do jongo; ponto de demanda ou porfia - para desafio; ponto de gurumenta ou gromenta - para briga; ponto encante - para magia (RIBEIRO, 1984, p. 23).

No passado escravista, por meio dos pontos de jongo, pessoas escravizadas foram capazes de combinar fugas, refletir, comparar, criticar e reagir ao cotidiano de opressão e violência imposto pela escravidão a partir da celebração de alianças e desafetos. Por possuírem mensagens cifradas e enigmáticas, os pontos devem ser decifrados, ou como se diz na linguagem dos jongueiros, desatados. Se ninguém conseguir desatar, os jongueiros dizem que o ponto ficou amarrado, ou seja, não conseguiu ser decifrado por ninguém (RIBEIRO, 1984).

Com suas raízes relacionadas aos saberes africanos, envolve um modo diferente de ver o mundo, apresentando influência do grupo linguístico banto. Grande parte dos africanos vindos para o atual Sudeste do Brasil veio de sociedades desse grupo linguístico, principalmente da atual Angola e do Congo-Norte (SLENES, 1999). De acordo com LOPES (2011), os bantos constituem "muito mais do que uma etnia ou grupo étnico, devendo ser vistos como um grande conjunto de povos falantes de línguas que têm uma origem comum" (LOPES, 2011, p. 96).

Para os bantos, a noção de força vital é muito importante, podendo ser transmitida inclusive para seres inanimados, tornando compreensível a importância dos tambores no jongo, que são extremamente respeitados. Outro elemento ressaltado é a importância que os povos bantos atribuem à ancestralidade. Para esses povos, os ancestrais são onipresentes, evidenciando a importância da pessoa idosa e o reconhecimento de sua autoridade, que vem dessa relação com a ancestralidade (LOPES, 2011). 
Essas influências banto são perceptíveis no jongo. Não raras entre os jongueiros são as histórias de bananeiras ${ }^{1}$ que nasciam na madrugada e davam frutos aos presentes, os relatos da presença dos pretos-velhos nas rodas de jongo, ou ainda as histórias dos encantamentos através dos pontos, reforçando o caráter mágico, poético, enigmático e religioso.

O contexto colonial e de escravidão é parte da conjuntura histórica de origem do jongo, que nasce como uma expressão cultural rural. Com a abolição e a migração da população anteriormente escravizada para as periferias das cidades, seus mantenedores vão, a partir do jongo, reelaborar táticas sutis e enviesadas de manutenção desses saberes e fazeres insubmissos e reativos, que se remetem a uma África ancestral, sendo estes muitas vezes mantidos sob a égide do segredo, enquanto tática de resistência (CERTEAU, 1990) ao sistema dominante.

Sobre a relação histórica entre o jongo e a religiosidade, Robert W. Slenes (2007) fala sobre os jongueiros cumba:

Para praticantes do complexo musical "jongo" em meados do século $\mathrm{XX}$, quando Stein e Borges Ribeiro fizeram suas pesquisas, "cumba" tinha a conotação de "mágico, mestre do feitiço". O jongueiro cumba carregava seus "pontos" ("versos", mas literalmente "fios e laçadas de costura" - como aqueles de tropeiros em arreios) com poderes especiais: em particular os pontos-enigma de desafio ("demanda"), lançados para provocar seus pares. Procuro mostrar que "cumba" evocava para os escravos do século XIX um rico conjunto de significados, enraizado na cultura centro-africana (SLENES, 2007, p. 109-110).

Silva (2006) realizou um estudo sobre representações existentes em diferentes relatos sobre o jongo, evidenciando "os conflitos de interesses e o choque entre essas diferentes representações e leituras de uma mesma manifestação, expressos por meio do discurso explícito ou pela codificada linguagem compartilhada pelos mantenedores desse saber" (SILVA, 2006, p. 163). Carmo (2015) apresenta algumas reflexões, com base nos debates ocorridos durante a 9a Reunião de Articulação das Lideranças das Comunidades Jongueiras, no ano de 2010, na roda de conversa "Jongo, religiosidade e matriz africana". Um dos relatos ressaltado pela autora foi o de Eva Lúcia, jongueira de Barra do Piraí-RJ, que diz:

[...] Chegou até esse debate exatamente porque na última reunião que nós tivemos aqui, eu falei sobre a mistura de jongo e usei o termo, que se diz pejorativo, macumba, né? Eu queria explicar pra vocês que na hora que eu falei aquilo, em momento nenhum estava discriminando nenhuma religião. Até porque todo jongueiro sabe das origens do jongo, que é também a minha origem. Só que eu acho... esse é um pensamento meu... que todos dois, tanto o espiritismo ou a umbanda, o candomblé, seja lá o que for, é uma cultura de matriz africana e, assim como o jongo também, todos vieram do mesmo lugar. Nós somos negros, todos vieram até aqui do mesmo jeito e todas as culturas negras vieram com os negros, todos saíram do mesmo lugar. Só que, por exemplo, o Toninho Canecão tem um tambor de jongo, tem uma capela com seus santos, 
tem um centro de umbanda, tem os tambores do jongo, tem os atabaques do terreiro de umbanda e na hora que ele tá com a religiosidade dele e fazendo lá o ritual ele, ele está fazendo um ritual de umbanda que é a religiosidade dele. E na hora que ele tá fazendo a roda de jongo dele, ele tá fazendo a roda de jongo dele. E eu acho que uma coisa é uma coisa. Outra coisa é outra coisa. Você não pode pegar os seus tambores, tirar de lá de dentro do santo, do centro e botar lá no meio da roda de jongo e bater o seu atabaque de umbanda dentro da roda de jongo. Assim como você não pode fazer isso com os tambores de jongo. Eu não posso chegar no meio de uma sessão espírita pegar o meu tambor de jongo e entrar dentro do centro e bater o meu jongo e cantar lá no ritual de umbanda ${ }^{2}$ (CARMO, 2015, p. 2).

A autora explica que Eva Lúcia faz esse relato após as falas de Toninho Canecão, do Quilombo de São José da Serra e de Délcio José Bernardo, consultor do Pontão de Cultura do Jongo/Caxambu e colaborador do Grupo de Jongo do Quilombo Santa Rita do Bracuí. As falas de Toninho e Délcio apresentam um discurso de aproximação do jongo com a religiosidade. A autora reproduz o seguinte relato proferido por Toninho:

[...] hoje, graças a Deus, a gente adquiriu um respeito no município de Valença. Por que a gente adquiriu esse respeito? Porque nós assumimos, tá? Porque quem nega a sua raiz eu vejo assim... negar a sua raiz é o maior crime que a gente tá fazendo... é negar a raiz, tá? Claro que muita gente gostaria de dizer assim "Ah, o jongo não tem nada com o espiritismo". Só que escondidinho, na calada da noite, ele está lá, sentado no toco do preto velho e pedindo a bênção, e pedindo pra não falar pra ninguém que eu estive aqui, tá? Então isso acabou na nossa comunidade, graças a Deus. Então hoje vai o padre celebrar missa lá na nossa comunidade. $\mathrm{O}$ tambor que tá batendo lá no centro ele desce e bate dentro da igreja e o pessoal tá até com os olhos meio russo de passar a noite toda lá cantando, dançando para o guia e participa da missa e são respeitados3 (CARMO, 2015, p. 3).

Os relatos reforçam essa heterogeneidade nos discursos dos jongueiros quando se trata da relação entre jongo e religiosidade. De acordo com SLENES (2007), "o preconceito estabelecido na sociedade brasileira diante das religiões de matriz africana fez com que, no século XX, os jongueiros desenvolvessem a tendência de negar qualquer forma de ligação do jongo com a macumba" (SLENES, 2007, p. 154).

Porém, concordamos com Carmo (2015), quando diz:

A negação da relação do jongo com as religiões de matriz africana por alguns jongueiros não significa necessariamente a ausência dessa relação na prática. Ela pode ser um indício da existência do segredo, muito presente no discurso mágico, onde o acesso a certos fundamentos é restrito a um determinado grupo. É provável que para um mesmo grupo de jongueiros exista diferentes formas de apresentar o jongo. $\mathrm{O}$ que definiria o modo de apresentação seria o público para qual se apre- 
senta. A apresentação de jongo para um grupo de alunos que nunca teve contato com a dança pode não ser a mesma realizada para um público formado por jongueiros e simpatizantes da dança, como acontece nos Encontros de Jongueiros (CARMO, 2015, p. 4).

No próximo tópico, com base nessa reflexão sobre as diferentes representações e leituras do jongo relacionadas à questão da religiosidade, descreveremos o jongo de tradição familiar da mestra jongueira Noinha, refletindo sobre as situações de discriminação e preconceito étnico-raciais por ela relatadas enquanto contingências reais para a própria manutenção e transmissão desses saberes.

\section{JONGO DE TRADIÇÃO FAMILIAR E RESISTÊNCIA}

A mestra jongueira Noinha possui o jongo como tradição familiar tanto na família materna quanto na família paterna. O terreiro de jongo da família materna era no bairro do Caju, em Campos dos Goytacazes-RJ. Já o terreiro de jongo da família paterna era em Santa Cruz, na mesma cidade. A família de Noinha residiu no bairro do Caju até o ano de 1954, quando, aos 10 anos de idade, mudou-se para o bairro Parque Guarus, localizado às margens da cidade, onde reside até a atualidade.

O surgimento do terreiro de jongo no Parque Guarus ocorreu em 1987. Com o falecimento dos familiares mais antigos, Maria Antônia, mãe de Noinha, incentivada pelas filhas, iniciou o contato com jongueiros do bairro e adjacências para iniciar o novo terreiro. Posteriormente, com o falecimento da mãe, no ano de 1991, Noinha assumiu o terreiro de jongo em Campos dos Goytacazes-RJ e a irmã em Niterói-RJ. Jongo Congola I e Congola II tem a "mesma raiz", diz Noinha.

Nas palavras da mestra jongueira:

Mestre jongueira no jongo de terreiro é, ele vem de família. Um falece e o outro pega o espaço desde que ele tenha compromisso. Então o meu avô era mestre jongueiro, a minha mãe passou a ser mestre jongueira depois que meu avô faleceu, muito tempo, aí se organizou o jongo. A minha mãe faleceu, eu assumi aqui em Campos e a minha irmã em Niterói, que eles tem um grupo lá, que aqui a gente coloca o nome Congola I e o de lá é o Congola II (NOINHA, 2015).

Lopes (2011) diz que "da mesma forma que 'samba' viria de semba, ‘jongo' parece vir de ndjongo, termo quimbundo que significa, segundo o Dicionário do Pe. Alves, 'criação, descendência' e que teria, aqui, tomado o sentido de 'reunião de familiares'” (LOPES, 2011, p. 188).

Oliveira (2011), a partir da experiência do jongo de Barra do Piraí, diz que a institucionalização do patrimônio imaterial traz o diferencial da garantia de direitos culturais por meio de políticas públicas, porém, é a sabedoria transmitida e cultivada nas bases familiares dos grupos e comunidades que mantém o jongo vivo. E essa família não necessariamente está vinculada às relações consanguíneas. 
Essa concepção ampliada, estendida e extensiva de família também está presente no jongo de Noinha, que conta com a participação não apenas de familiares que compartilham laços biológicos, mas também com a presença de amigos e filhos adotivos. Em suas palavras:

Mas a família que eu falo, quando eu falo família, não é consanguínea né, eu não sou muito achar que a família é consanguínea. Família é o amor né, família é o amor. Pra isso eu criei meus filhos, eu sempre disse a eles, eu dou a base, mas não vou dar muito a poucos, porque tem muitos precisando (NOINHA, 2018).

Para Fonseca (2005), “a relação indivíduo-família não pode ser pensada da mesma forma em todo lugar, pois a própria noção de família varia conforme a categoria social com qual estamos lidando" (FONSECA, 2005, p. 52). Considerando os estudos de Duarte (1994) ${ }^{4}$, a autora ressalta que

[...] o valor "família" tem grande peso em todas as camadas da população brasileira. No entanto, significa coisas diferentes dependendo da categoria social. Enquanto, entre pessoas da elite, prevalece a família como linhagem (pessoas orgulhosas de seu patrimônio), que mantêm entre elas um espírito corporativista, as camadas médias abraçam em espírito e em prática a família nuclear, identificada com a modernidade. Para os grupos populares o conceito de família está ancorada nas atividades domésticas do dia a dia e nas redes de ajuda mútua (FONSECA, 2005, p. 51).

O jongo de tradição familiar forma laços de solidariedade que tem como base relações de memória e afeto. O cotidiano dessas relações familiares ampliadas não aparece apenas como espaço de reprodução da vida social, mas também como possibilidade de superação e trocas. Essas relações familiares extensivas e comunitárias agem enquanto forma de recriação de ascendências africanas, também presentes em outras expressões culturais e religiões afro-brasileiras (SILVA, 2005; THEODORO, 2009). Pensando a transmissão familiar do jongo como uma possibilidade de manutenção da expressão cultural, Noinha insere a participação de seus netos nas rodas. Nesse jongo, ser criança não é um impeditivo para participar. Sobre as relações de aprendizagem intergeracional, Oliveira (2011) diz que os mais velhos são muito respeitados e referenciados como mestres,

o que nos remete à tradição africana de culto ao ancestral. A representatividade dos mestres é tanta entre os jongueiros, e o jongo é algo tão presente na vida construída, que os laços ganham uma conotação familiar, o convívio, o respeito e a admiração fazem com que muitos sejam chamados de tio, tia, irmão e até pai, mesmo sem haver laços biológicos (OLIVEIRA, 2011, p. 7).

Ao assumir o terreiro de jongo da mãe, Noinha recria práticas dos mais velhos, que recorda dos tempos da infância, como a relação dos 
familiares com a terra e com seus locais de moradia. O jongo da mestra jongueira Noinha e as relações familiares travadas a partir dele possuem um espaço privilegiado de ação: o terreiro de jongo, o chão de terra batida, o quintal da casa, que é visto não apenas como local do jongo, mas também como local de sociabilidade da família numa concepção extensa, contemplando o jongo, a religiosidade e outras expressões do cotidiano.

Muniz Sodré, no vídeo O Espaço da África no Brasil ${ }^{5}$, chama a atenção para o fato de que, para várias culturas não hegemônicas, não é o tempo o eixo de organização da vida mais importante, mas sim o espaço, a relação com a terra. O eixo centralizado no espaço aparece na cultura afro-brasileira como característica de uma cultura de diáspora que precisava se territorializar.

Leite (1997), falando sobre valores civilizatórios em sociedades negro-africanas ${ }^{6}$, indica "a existência histórica de uma convergência civilizatória crucial para a captação da identidade mais decisiva de sociedades da África negra e para a captação do sentido de processos sociais específicos" (LEITE, 1997, p. 103), que fazem parte da forma de interpretar o mundo e da organização histórica da realidade. Essa reflexão é importante para analisarmos os históricos e múltiplos processos de hibridização cultural e recriação de saberes e fazeres afro-brasileiros. Segundo Leite (1997), na África a própria noção de ser humano está umbilicalmente ligada a conceitos como força vital, palavra, família, poder e ancestralidade que, por sua vez, ganham sentido na territorialização das relações sociais em comunidade.

A terra, principal recurso natural dessas sociedades agrárias, é considerada ela mesma como uma divindade e sua fertilidade é tomada como doação preexistente. Dotada dessa energia vital que a sacraliza, a terra não pode ser apropriada pelo homem, que, entretanto, está potencialmente habilitado a ocupá-la segundo as normas ancestrais (LEITE, 1997, p. 112).

Nessa perspectiva, direcionamos nosso olhar para o terreiro de jongo de Noinha, o espaço do quintal que, além de ser local do jongo, também é um lugar específico de afetividade, de sociabilidade familiar, de relação com as plantas e com os animais, de religiosidade, onde todo o cotidiano ocorre, onde a vida social acontece e se organiza. Podemos pensar esse espaço como local de resistência dotado de práticas específicas.

Ingold (2015) nos adverte que habitar um lugar implica banhar os corpos na luz, nos sons e sentimentos, algo que está para além de meramente ocupar ou consumir estruturas existentes. Segundo o autor, habitar "significa antes essa imersão dos seres nas correntes do mundo da vida, sem a qual atividades como concepção, construção e ocupação não poderiam acontecer" (INGOLD, 2015).

Fonseca (2005) ressalta que para muitas dessas famílias das camadas populares, as relações familiares são pensadas para muito além da "casa", sendo consideradas em termos de "pátio". Sobre essa questão, ela diz que 
Em um terreno, por menor que seja, sempre tem lugar para construir mais uma "puxada", isto é, uma peça ou uma meia-água, para receber um amigo ou parente. A primeira moradia da maioria de jovens casais é uma peça construída no quintal dos pais ou sogros. Com filhos casando e descasando, pessoas mudando atrás de um novo emprego, ou simplesmente com a incorporação de algum inquilino, a composição do pátio muda (FONSECA, 2005, p. 53).

A mestra jongueira residiu em dois endereços no bairro Parque Guarus: o primeiro, na Avenida Beira Lago, endereço da casa para onde se mudou com a sua família, quando ainda era criança e que, posteriormente, foi transformado por ela no Centro de Cultura Afro-Brasileira Motorista Gordiano e Ilê D’Ogum Iara Polo I7; e o segundo, localizado na Avenida Campista, é o endereço onde reside atualmente. É possível transitar entre esses dois endereços, indo de uma casa à outra por dentro do terreno, transitando pela área do quintal que os une. Outros familiares também residem nesse entorno, transformando o espaço do quintal em um local de construção de relações e resistência cultural da família e da própria comunidade.

Refletindo sobre cultura negra, Sodré (2005) explica que "não se tratou jamais de uma cultura negra fundadora ou originária que aqui se tenha instalado para, funcionalmente, servir de campo de resistência" (SODRÉ, 2005, p. 92), já que para cá vieram dispositivos culturais correspondentes às várias nações ou etnias da África que, muitas vezes, já conheciam mudanças no próprio continente africano. Considerando a formação social brasileira, o autor diz que "é o caso patente, palpável de coexistência e interpenetração multisseculares de duas ordens culturais, a branca e a negra, funcionando esta última como fonte permanente de resistência" (SODRÉ, 2005, p. 92). E é justamente por meio da resistência, da busca de recriar e reviver seus saberes e fazeres que a religiosidade age para a manutenção do grupo.

Moura (1995) diz que:

A aproximação dos cultos negros com o catolicismo se daria desde o início da escravatura, [...]. Tal aproximação se inscreveria de forma complexa tanto nas religiões africanas atualizadas pela vida brasileira, como nas novas religiões negro-brasileiras, resultado do encontro do negro com seus novos interlocutores, sejam eles os brancos senhores, ou mestiços, índios, ou mesmo outros brancos encontrados em situações de paridade social a partir do processo abolicionista (MOURA, 1995, p. 128).

A religião é muito importante na vida de Noinha. Conta que em sua família existem pessoas de várias religiões diferentes. Sua avó materna, Margarida, era do candomblé, responsável pelo preparo das comidas sagradas $^{8}$ dos orixás. Guarda lembranças de um tempo em que não tinha muita afinidade com a sua avó por questões religiosas, já que foi criada na religião católica e tinha medo do que não conhecia. Explica que esse afastamento da avó fez com que perdesse muitos ensinamentos. 
Foi só depois de ser mãe que passou a frequentar a umbanda, pela filha Fabrícia, falecida em 19 de agosto de 1977. Noinha diz que foi a espiritualidade que a preparou para a passagem da filha. Sobre o fato, ela diz:

Se eu não tivesse, não conhecesse a religiosidade que hoje eu conheço, eu não aguentaria. Então, eu acho que o espírito dela mesmo, a alma dela, o envolvimento dela espiritual que era muito forte, me preparou. Então me converti (NOINHA, 2018).

Quando a filha tinha mais ou menos dois anos de idade, sentia dores que nenhum remédio conseguia amenizar. Foram muitas consultas e exames sem que nada fosse descoberto. Foi aí, quando não encontrou respostas na medicina, que ela foi buscar em outros lugares uma explicação. Noinha diz:

Mas se você tiver uma força, ou fé, sei lá de qual religião seja, ou não ter religião. Eu acho que a fé é muito maior do que a religião. Religião é aquele templo onde você se encontra, mas com a influência de amigos, a parte social. Eu acho que o templo é a parte social, é a religião. Agora a fé é muito importante. Se a gente tem fé, a gente passa as coisas, as coisas ficam mais suaves. A gente não se desespera e espera aquilo acontecer. Se for positivo, e se for negativo a gente passa e dá a volta por cima. E se a gente não tiver fé, aí desmonta. Qualquer um de nós. Então se eu creio que as coisas que estavam determinadas pra eu passar, se antes não tivesse me mostrado esse outro lado da moeda, eu não aguentaria. Então eu devo muito, muito, muito, muito... Devo muito às entidades. Devo muito ao meu preto velho, que me sustenta, que me apoia espiritualmente. E meus familiares materialmente. É isso (NOINHA, 2015).

Noinha relata que o jongo para ela é uma maneira de conscientizar as pessoas e de crescer como ser humano. A mestra explica que o jongo é a sua própria alma e, que quando grita seus pontos de jongo, a primeira coisa que pensa é na voz sufocada dos avós, que não tiveram oportunidade de falar sobre o que passaram. Por isso, os pontos que canta são sempre uma libertação para ela. Sobre a relação entre jongo e religiosidade, Noinha, quando questionada se os seus ancestrais estão juntos dela no jongo, diz:

Se eles estiverem aí, porque, porque, a espiritualidade anda muito mais rápido do que a gente, não é. Eu não vou dizer que eles não estão porque, né... é uma força né, uma vibração, é o espaço que se eles, se acharem que estão bem, né, que eles podem estar ali, só que eu não evoco. A minha parte de dança é dança (NOINHA, 2015).

Mas, se o quintal é o espaço da afetividade e do cotidiano, aparece também como um território atravessado por disputas. Uma das disputas identificadas nesse território tem relação direta com a questão da religiosidade. Noinha já foi vítima de intolerância religiosa em sua comunidade e sobre isso fez o seguinte relato: 
Eu já tinha aqueles dias certos de passe, então aí a gente fazia uma palestra antes, conversava com algumas pessoas, orientação religiosa, porque isso é muito importante pra mim. Antes da outra, aí, depois do bate-papo, da conversa religiosa, aí que a gente fazia o passe, aí o preto velho chegava e dava o passe pro pessoal. Aí eles sabiam mais ou menos o horário e o dia. Pegava uma, era Kombi, hoje eles tem van de igreja, ficava com alto-falante em frente o meu portão. Com a altura maior que pudesse, o volume maior. Chegou um dia, não veio a van, a Kombi da igreja. Aí chegava na outra semana, eles cruzavam, fazia um culto do lado, numa casa do lado, fazia outro culto na casa da frente. Chegou um tal dia que não veio a van, o transporte da igreja. Eu achei assim, uma coisa engraçada. Aí de repente, um carro com uns alto-falantes, mas muito possante mesmo, começou a gritar música gospel. [...] Tentavam botar os vizinhos contra mim. Pessoa que a gente foi criado junto (NOINHA, 2015).

Considerando o chamado "tripé pentecostal contemporâneo", do qual fazem parte a teologia da prosperidade, a guerra espiritual e a flexibilização dos costumes, Sales (2017) explica que, para os neopentecostais, o sucesso na guerra espiritual depende também da moralização dessa guerra onde, principalmente, as religiões afro-brasileiras são desmoralizadas e consideradas demoníacas.

Sobre o avanço neopentecostal, o autor diz:

Apenas entre 2000 e 2010, os evangélicos cresceram cinco vezes mais do que a população brasileira, $61,4 \%$ contra $12,3 \%$. Dos 42,3 milhões de evangélicos em números absolutos, 25,4 milhões, ou 13,3\% da população brasileira, é composta por evangélicos pentecostais, cifra bem mais considerável do que o terceiro maior grupo de evangélicos, isto é, os evangélicos de missão, que somam $4 \%$ da população brasileira. O maior responsável pelo grande crescimento dos evangélicos na última década é o sucesso pentecostal no país. Não foi apenas o crescimento das igrejas pentecostais, mas, principalmente, a nova forma de relacionamento com o transcendente que a "terceira onda" do pentecostalismo - a saber, o neopentecostalismo - gerou na sociedade brasileira (SALES, 2017, p. 14).

Vagner Gonçalves da Silva (2005) explica que nas últimas duas décadas tem-se verificado no Brasil uma intensificação do ataque promovido pelas igrejas neopentecostais contra as religiões afro-brasileiras. $\mathrm{O}$ autor explica que:

esse ataque, visto por seus agentes como uma "guerra santa" ou "batalha espiritual" do bem contra o mal (sendo este representado pelos demônios que se travestem preferencialmente de divindades do panteão afro-brasileiro para causar malefícios), faz parte, em diferentes graus, do sistema teológico e doutrinário do pentecostalismo desde seu surgimento no Brasil no início do século XX (SILVA, 2005, p. 151).

Mais do que uma estratégia de proselitismo junto às populações de baixo nível socioeconômico, o autor explica que esse ataque visa combater essas religiões "para monopolizar seus principais bens no merca- 
do religioso, as mediações mágicas e a experiência do transe religioso, transformando-o em um valor interno do sistema neopentecostal" (SILVA, 2005, p. 152).

No estado do Rio de Janeiro, o Centro de Promoção da Liberdade Religiosa \& Direitos Humanos - CEPLIR é o responsável pelo atendimento às vítimas de intolerância religiosa, por meio de registro de denúncias de forma presencial e por telefone, prestando atendimento de apoio jurídico, psicológico e social aos seus usuários. Com relação a dados estaduais, o documento Intolerância Religiosa no Brasil: Relatório e Balanço (2016) apresenta que os indicadores de referência são do período de julho de 2012 a setembro de 2015 (totalizando 1.014 atendimentos) e setembro a dezembro de 2015 (totalizando 66 atendimentos). No primeiro momento de investigação, os praticantes de religiões afro-brasileiras eram as maiores vítimas, em que "as denúncias contra religiões afro-brasileiras representaram $71,15 \%$, fato que indica este segmento como o mais vulnerável e consequentemente aquele com maior índice de vitimização" (SANTOS et al., 2016, p. 24-25).

A cidade de Campos dos Goytacazes, no interior do estado do Rio de Janeiro, tem vivenciado essa realidade de aumento dos ataques contra as religiões afro-brasileiras. Em setembro de 2019, foi publicada uma reportagem ${ }^{10}$ onde o prof. dr. Babalawo Ivanir dos Santos relata que dos 200 centros de religiões de matriz africana ameaçados em todo o estado, 40 estão localizados no município, evidenciando a grave situação.

Com base nas palavras do líder religioso, a reportagem ressalta que:

Campos vive, hoje, a situação mais grave do estado, com ameaças, mortes e também perseguições. Pode-se dizer que a região superou cidades da Baixada Fluminense, que sempre registraram um forte histórico de ataques a terreiros (AMORIM, 2019).

A reportagem também apresenta a fala do delegado Gilbert Stivanello, da Delegacia de Crimes Raciais e Delitos de Intolerância (Decradi). A reportagem ressalta a seguinte fala do delegado:

Os assassinatos estão sendo investigados para chegarmos à motivação. Os casos de Campos não foram comunicados à Decradi, que fica a quatro horas de distância daqui, fazendo que as pessoas optem por registrar a ocorrência na delegacia local. Nós vamos entrar em contato com a polícia de lá para apurar mais a motivação. O que temos são cerca de 20 ataques investigados na Baixada Fluminense (AMORIM, 2019).

A discussão em torno das religiões afro-brasileiras, dos impactos do crescimento neopentecostal e da intolerância religiosa é muito profunda e complexa, não sendo possível esgotá-la neste artigo. Podemos compreender que historicamente "a demonização das religiões de matrizes africanas esteve imbricada ao racismo. A discriminação racial, que justificava ideologicamente a escravização dos africanos, se estendia à religiosidade vinda da África, que foi desqualificada e associada à feitiçaria europeia" (LIMA; MOLINA; SILVA, 2013). 
De acordo com Almeida (2018) o racismo, "é uma forma sistemática de discriminação que tem a raça como fundamento, e que se manifesta por meio de práticas conscientes ou inconscientes que culminam em desvantagens ou privilégios para indivíduos, a depender do grupo racial ao qual pertençam" (ALMEIDA, 2018, p. 25). O autor também argumenta que o racismo é sempre estrutural, no sentido de constituir elemento que integra a organização econômica e política da sociedade brasileira, fornecendo o sentido, a lógica e a tecnologia para as formas de violência que moldam a vida social contemporânea, onde "as expressões do racismo no cotidiano, seja nas relações interpessoais, seja na dinâmica das instituições, são manifestações de algo mais profundo, que se desenvolve nas entranhas políticas e econômicas da sociedade" (ALMEIDA, 2018, p. 16).

Segundo Eurico (2013) o racismo institucional se expressa na dificuldade de "acesso à escola, ao mercado de trabalho, na criação e implantação de políticas públicas que desconsideram as especificidades raciais e na reprodução de práticas discriminatórias arraigadas nas instituições" (EURICO, 2013, p. 299). Ainda segundo a autora, a situação social das mulheres negras é marcada pela violência contra si, seu corpo e sua vida, e também pela violência que atinge seus filhos, irmãos, companheiros, netos, bisnetos, massacrados pelos números da violência no Brasil, que mata majoritariamente a população negra. Considerando a persistência dos números relativos à violência apresentados no Atlas da Violência 2019 e a continuidade do processo de aprofundamento da desigualdade racial nos indicadores de violência letal no Brasil, onde, em 2017, 75,5\% das vítimas de homicídios foram indivíduos negros (IPEA, 2019 , p. 46), torna-se extremamente importante tematizar e disseminar o debate do tema racial atrelado a uma proposta coletiva que promova uma cultura da vida, da paz, da liberdade, do respeito religioso, da democracia e dos direitos humanos.

Se o racismo age enquanto ideologia que justifica, naturaliza e dessensibiliza a população para compreender e se opor às históricas desigualdades hierárquicas, econômicas, sociais e educacionais decorrentes dos quatro séculos de escravidão no Brasil, compreendemos que o jongo e seus saberes e fazeres permitem que pessoas negras, em especial, mulheres negras, construam espaços de manutenção e recriação de seus saberes e fazeres, por meio dos quais as sociabilidades, trocas e exercício de poder lhes permitem agir no enfrentamento das dificuldades e contingências cotidianas. Por isso, as soluções que mulheres como a mestra jongueira Noinha encontram para resolver suas questões precisam ser colocadas em evidência, descritas e analisadas, para que possamos anunciar possibilidades inspiradoras de existência.

\section{CONSIDERAÇÕES FINAIS}

Contar a história de como a mestra jongueira Noinha mantém o jongo em seu quintal é contar um pouco da história de Campos dos 
Goytacazes, mas uma "história que a História não conta", ou que, pelo menos, não conta tanto quanto deveria. A história do jongo é permeada pela escravidão, resistências, violências, afetos, dificuldades e também superações. É contar um pouco da história do povo negro.

As ações de valorização e visibilização do jongo enquanto expressão cultural afro-brasileira tem relação direta com a melhoria das condições de vida das pessoas que o mantém. Desde 2005 o jongo é reconhecido como patrimônio cultural imaterial do Brasil. Sendo esse reconhecimento fruto de um processo coletivo, o processo de formulação e aplicação das políticas públicas de salvaguarda também precisa passar a envolver as comunidades jongueiras, voltando-se para as realidades de seus mantenedores e ao atendimento de suas demandas específicas, visando a alteração dos condicionantes das desigualdades, buscando assim compreender e construir a aplicação conjunta de políticas públicas.

No desenrolar investigativo sobre o jongo de Campos de Goytacazes, chegamos aos espaços dos quintais, concebidos como espaços centrais na discussão não apenas da realização do jongo, mas da manutenção da própria vida da mestra jongueira Noinha e de seus familiares. Torna-se extremamente importante ressaltar também, para pesquisas futuras, a necessidade de mapeamento do jongo e dos jongueiros em outras localidades de Campos dos Goytacazes-RJ e região, em busca das histórias e saberes não desvelados e das necessidades e demandas de seus mantenedores. Mapear esses jongueiros é conhecer as ações de resistência e luta tanto pela visibilização e valorização dessa expressão cultural, quanto por melhores condições de vida para a própria população negra da cidade, em especial, suas mulheres. Parafraseando o samba-enredo da Mangueira ${ }^{11}$ e sua genialidade: "Brasil chegou a vez de ouvir as Marias, Mahins, Marielles, malês”.

\section{NOTAS}

1. Lilian Sagio Cezar (2015), em seu artigo A santa, o mar e o navio: congada e memórias da escravidão no Brasil, explica que assim como na congada, "metáforas, dessa vez envolvendo bananeiras, cobra e insetos zumbidores, contribuem para ligar os jongos a um mundo centro-africano" (apud SLENES, 2007, p. 133).

2. De acordo com o trabalho, a referência é: DVD nº 3.00088 - Acervo Pontão de Cultura do Jongo/Caxambu.

3. De acordo com o trabalho, a referência é: DVD nº 3.00088 - Acervo Pontão de Cultura do Jongo/Caxambu.

4. DUARTE, L. F. D. Horizontes do indivíduo e da ética no crepúsculo da família. In: RIBEIRO, I. (org.). Família e sociedade brasileira: desafios nos processos contemporâneos. Rio de Janeiro: Fundação João XXIII, 1994. p. 23-41.

5. Disponível em: <https://www.youtube.com/watch?v=8asUpAkFbu4>. Acesso em: 26 jun. 2019. 
6. O autor explica que os tópicos enunciados por ele para tratar desses valores "referem-se prioritariamente e muito sinteticamente a três sociedades da África ocidental - Yoruba, Agni (grupo Akan) e Senufo - civilizações agrárias que, entretanto, se distinguem fortemente em virtude de suas organizações políticas, pois que, enquanto os Yoruba e Agni se constituem em sociedades dotadas de Estado, entre os Senufo essa figura não se caracteriza" (LEITE, 1995/1996, p. 103). Porém, o autor também explica que "parece certo que são aplicáveis, com a cautela devida às individualidades, a um número não negligenciável de sociedades negro-africanas" (LEITE, 1995/1996, p. 103-104). Por esse motivo, inserimos essa discussão.

7. Disponível em: <https://www.google.com/maps/place/Centro+de+Cultura+Afro-Brasileiro+Motorista+Gordiano+e+Il\%C3\%AA+D'Ogum+Ia$\mathrm{ra}+$ Polo+I/@-21.7155329,-41.3223923,15z/data $=$ !4m5!3m4!1s0x0:0x838165525d62592b!8m2!3d-21.7155329!4d-41.3223923>. Acesso em: 21 out. 2020.

8. Iyá bassé (iyábasé) - responsável pelo preparo das comidas sagradas, desde os sacrifícios até a entrega aos orixás. Cargo que poderá ser dado a qualquer pessoa iniciada de uma divindade feminina (ODÉ; VERA, 2009).

9. De acordo com Sales (2017), Mariano (1999) classifica o pentecostalismo em três ondas: pentecostalismo clássico, deuteropentecostalismo, e neopentecostalismo. Para Mariano a transformação que as "ondas" geraram está ligada ao processo de aculturação das teologias importadas, fundamentais para tornarem o pentecostalismo uma religião "brasileira" (SALES, 2017, p. 14).

10. AMORIM, Diego. Líderes religiosos de Campos relatam ataques e ameaças de traficantes a terreiros. Extra, 10 set 2019. Disponível em: $<$ https://extra.globo.com/casos-de-policia/lideres-religiosos-de-campos-relatam-ataques-ameacas-de-traficantes-terreiros-23938758.html>. Acesso em: 25 out. 2020.

11. História para ninar gente grande. Compositores: Deivid Domênico, Tomaz Miranda, Mama, Márcio Bola, Ronie Oliveira, Manu da Cuica e Danilo Firmino. Grêmio Recreativo Escola de Samba Estação Primeira de Mangueira. Rio de Janeiro, 2019.

\section{REFERÊNCIAS}

ALMEIDA, Silvio Luiz de. O que é racismo estrutural? Belo Horizonte: Letramento, 2018.

AMORIM, Diego. Líderes religiosos de Campos relatam ataques e ameaças de traficantes a terreiros. Extra, 10 set 2019. Disponível em: <https://extra.globo.com/casos-de-policia/lideres-religiosos-de-campos-relatam-ataques-ameacas-de-traficantes-terreiros-23938758.html>. Acesso em: 25 out. 2020.

CARMO, Ione Maria do. Entre o discurso e a prática: o debate em torno da relação jongo e religiosidades e a performance no Encontro de Jongueiros. In: SIMPÓSIO NACIONAL DE HISTÓRIA, 28, 2015, Florianópolis. Anais... Florianópolis: Associação Nacional dos Professores Universitários de História - Anpuh, 2015. Disponível em: < http:// www.snh2015.anpuh.org/resources/anais/39/1439866345_ARQUIVO_TextocompletoAnpuh2015.pdf>. Acesso em: 22 abr. 2019. 
CERTEAU, Michel de. A invenção do quotidiano. Petrópolis: Vozes. 1990. CEZAR, Lilian Sagio. O velado e o revelado: imagens da Festa da Congada. Tese (Doutorado) - Programa de Pós-Graduação em Antropologia Social, Universidade de São Paulo, 2010. Disponível em: <http:// www.teses.usp.br/teses/disponiveis/8/8134/tde-10082010-134150/ pt-br.php>. Acesso em: 02 jul. 2019.

DEUS, Lucas Obalera de. Por uma perspectiva afrorreligiosa: estratégias de enfretamento ao racismo religioso. Rio de Janeiro: Fundação Heinrich Böll, 2019. Disponível em: <https://br.boell.org/sites/ default/files/caderno_religiao_e_politica_lucas_de_deus_boll_brasil_.pdf>. Acesso em: 02 jul. 2019.

DUARTE, L. F. D. Horizontes do indivíduo e da ética no crepúsculo da família. In: RIBEIRO, I. (org.). Família e sociedade brasileira: desafios nos processos contemporâneos. Rio de Janeiro: Fundação João XXIII, 1994. p. 23-41.

EURICO, Márcia Campos. A percepção do assistente social acerca do racismo institucional. Serviço Social \& Sociedade, n. 114, p. 290310, jun. 2013. Disponível em: <http://dx.doi.org/10.1590/s010166282013000200005>. Acesso em: 11 jun. 2019.

FONSECA, Cláudia. Concepções de família e práticas de intervenção: uma contribuição antropológica. Saúde e Sociedade, v. 14, n. 2, p. 50 59, maio/ago. 2005.

INGOLD, Tim. Estar vivo: ensaios sobre movimento, conhecimento e descrição. Petrópolis: Vozes, 2015.

IPEA - INSTITUTO DE PESQUISA ECONÔMICA APLICADA. Atlas da violência 2019. Brasília; Rio de Janeiro; São Paulo: Fórum Brasileiro de Segurança Pública, 2019. Disponível em: <https://www.ipea. gov.br/portal/images/stories/PDFs/relatorio_institucional/190605_ atlas_da_violencia_2019.pdf>. Acesso em: 6 dez. 2021.

IPHAN - INSTITUTO DO PATRIMÔNIO HISTÓRICO E ARTÍSTICA NACIONAL. Dossiê Jongo no Sudeste. Brasília: Iphan, 2007. Disponível em: <http://portal.iphan.gov.br/uploads/publicacao/PatImDos_jongo_m.pdf>. Acesso em: 12 abr. 2019.

LEITE, Fábio. Valores civilizatórios em sociedades negro-africanas. África: Revista do Centro de Estudos Africanos, São Paulo: USP, v. 1, n. 18-19, p. 103-118, 1995/1996.

LIMA, Lana Lage da Gama. Rebeldia negra e abolicionismo. Rio de Janeiro: Achiamé, 1981. Série Universidade v. 19. Disponível em: <http:// bibliotecavirtual.camaracampos.rj.gov.br/index.php/component/flippingbook/book/357? page=1>. Acesso em: 22 abr. 2019.

LIMA, Lana Lage da Gama; MOLINA, Bernardo Berbert; SILVA, Leonardo Vieira. Racismo e discriminação religiosa em Campos dos Goytacazes: as dificuldades na aplicação da Lei Caó. Terceiro Milênio: Revista Crítica de Sociologia e Política, Campos dos Goytacazes, v. 1, n. 1, p. 33-47, 2013. Disponível em: <https://app.uff.br/riuff/ 
bitstream/handle/1/12148/Racismo_e_discriminacao_religiosa_ em_Cam.pdf;jsessionid=03774195587FECC4B362E96837C3549F?sequence $=1>$. Acesso em: 6 dez. 2021.

LOPES, Nei. Bantos, malês e identidade negra. 3. ed. Belo Horizonte: Autêntica Editora, 2011.

MOURA, Roberto. Tia Ciata e a Pequena África no Rio de Janeiro. Rio de Janeiro: Secretaria Municipal de Cultura - Divisão de Editoração, 1995.

NOINHA. Geneci Maria da Penha - Noinha: depoimento n. 1 [12 jun. 2015]. Entrevistadoras: Tarianne da Silva Pinto Bertoza, Lilian Sagio Cezar, Maria Clareth Gonçalves Reis. Campos dos Goytacazes-RJ: 2015. Entrevista realizada na Unidade Experimental de Som e Imagem - UESI.

NOINHA. Geneci Maria da Penha - Noinha: depoimento n. 2 [27 ago. 2018]. Entrevistadoras: Tarianne da Silva Pinto Bertoza, Lilian Sagio Cezar, Maria Clareth Gonçalves Reis. Campos dos Goytacazes-RJ: 2018. Entrevista realizada na residência da mestra jongueira Noinha durante trabalho de campo.

ODÉ, Kileuy; VERA de Oxaguiã. O candomblé bem explicado (Nações Bantu, Iorubá e Fon). Rio de Janeiro: Pallas, 2009. Disponível em: $<$ http://eceprab.com/blog/wp-content/uploads/2015/07/O-Candomble-bem-Explicado-George-Mauricio.pdf>. Acesso em: 25 jun. 2019.

OLIVEIRA, Luana da Silva. Memórias de patrimônio familiar: um estudo de caso sobre o jongo/caxambu. In: SIMPÓSIO NACIONAL DE HISTÓRIA, 26. 2011. Anais... São Paulo: Associação Nacional dos Professores Universitários de História - Anpuh, 2011. Disponível em: $<$ http://www.snh2011.anpuh.org/resources/anais/14/ 1308184985_ ARQUIVO_TextoAnpuh2011.pdf>. Acesso em: 22 abr. 2019.

PACHECO, Gustavo. Memória por um fio: as gravações históricas de Stanley J. Stein. In: LARA, Silvia Hunold; PACHECO, Gustavo (org.). Memória do Jongo: as gravações históricas de Stanley J. Stein Vassouras, 1949. Campinas: Cecult, 2007.

REIS, Maria Clareth Gonçalves. Mulheres, negras e professoras: suas histórias de vida. Campos dos Goytacazes: Brasil Multicultural, 2017.

RIBEIRO, Maria de Lourdes Borges. O jongo. Rio de Janeiro: Funarte/ Instituto Nacional do Folclore, 1984. Cadernos de Folclore 34.

SALES, João Ricardo Boechat Pires de Almeida. Religião e classe social: uma análise dos especialistas religiosos de diferentes segmentos evangélicos sob a influência do Pentecostalismo. Tese (Doutorado) - Programa de Pós-Graduação em Sociologia Política, Centro de Ciências do Homem, Universidade Estadual do Norte Fluminense Darcy Ribeiro, Campos dos Goytacazes, 2017. Disponível em: <http://uenf.br/posgraduacao/sociologia-politica/wp-content/ uploads/sites/9/2017/09/Disserta\%C3\%A7\%C3\%A3o-Joao-Boechat.pdf $>$. Acesso em: 02 jul. 2017.

SANTOS, Babalawô Ivanir dos et al. Intolerância Religiosa no Brasil: relatório e balanço. Rio de Janeiro: Kline Editora, 2016. Disponível 
em: <https://www.geledes.org.br/wp-content/uploads/2018/08/relatorio-final-port-2.pdf>. Acesso em: 22 abr. 2019.

SILVA, Adailton da. O Jongo no Rio de Janeiro: relatos de um pesquisador negro. Dissertação (Mestrado) - Departamento de Antropologia, Universidade de Brasília, Brasília-DF, 2006.

SILVA, Vagner Gonçalves. Candomblée Umbanda: caminhos da devoção brasileira. São Paulo: Selo Negro, 2005.

SLENES, Robert W. "Eu venho de muito longe, eu venho cavando": jongueiros cumba na senzala centro-africana. In: LARA, Silvia Hunold; PACHECO, Gustavo (org.). Memória do Jongo: as gravações históricas de Stanley J. Stein - Vassouras, 1949. Campinas: Cecult, 2007.

SLENES, Robert W. Na senzala uma flor: esperanças e recordações na formação da família escrava, Brasil Sudeste, Século XIX. Rio de Janeiro: Nova Fronteira, 1999.

SODRÉ, Muniz. A verdade seduzida: por um conceito de cultura no Brasil. Rio de Janeiro: DP\&A, 2005.

THEODORO, Helena. Guerreiras do Samba. Textos escolhidos de cultura e artes populares, Rio de Janeiro, v. 6, n. 1, p. 223-336, 2009.

SUBMETIDO EM: 08/07/2019

APROVADO EM: 13/10/2020 